\title{
Sobre las necesidades sociales y culturales: entre la necesidad constatada y la necesidad construida.
}

\section{Una aproximación al debate de las necesidades a propósito de las lógicas productoras de equipamientos socioculturales}

\author{
Xan Bouzada Fernández \\ Director del Insticuto Galego de Estudios Comunitarios \\ Universidad de Vigo. Deparramento de Socioloxía. Vigo. Spain
}

\section{Resumen}

El conrenido de esre arrículo ensaya una inmersión histórica y transversal en un concepto como el de necesidad que cuenta con unas ramificaciones constatablemente densas no sólo dentro del ámbico teórico de la sociología sino también en el de la antropología.

En primer lugat analizaremos los planteamientos mantenidos al respecto desde diferentes aproximaciones. Las teorías de autores pioneros como Durkheim o Malinowski, los postulados del funcionalismo sistémico, las tesis de algunos de los más significativos miembros de la Escuela de Francfurt y los debates suscitados e inspirados por posiciones tebricas con raices en el pensamiento marxista.

En segundo lugar analizaremos el concepto sociológico de necesidad realizando una lecrura rransversal basada en algunas de las contribuciones teóricas de los debates más recientes y dezeniéndonos de modo selectivo en las polémicas vividas actualmente en el campo de la sociologia de las necesidades y el trabajo social de comunidad.

Por úlrimo, intentaremos establecer un nexo que vincule la tradición de la teoria sociológica y las nuevas perspectivas de la sociología, teniendo en cuenta los problemas de orden práctico que se plantean tanto desde el ámbito del consumo y los equipamientos socioculturales, como desde la perspectiva de los movimientos sociales. (Autor)

Palabras clave: sociología teórica, trabajo social, comunidad.

\section{Abstract. On Social and Cultural Needs}

The contents of this article attempt to offer a historical interdisciplinary analysis of the concepr of necessity, which is not only very dense and productive within the sociological field, but also within the anthropological one.

Firstly, we will analyse the contributions to this subject from different approximations. The theories of pioneering authors such as Durkheim or Malinowski, the postulates of sistemic functionalism, the theses of the most important members of the Frankfurt School and the debates arisen by the theoretical approximations rooted in marxist thought.

Secondly, we will analyse the sociological concept of necessity giving an interdisciplinary perspecrive based on the theoretical contributions of most recent debates and making a profound selective study of the present controversy within sociology of necessity and local social work.

Finally, we will try to establish a nexus between sociological tradition and the now sociological perspectives, bearing in mind the specific problems of a practical kind yielded 
by consumerism and sociocultural equipments, and also by the perspective of social movements. (Autor)

Key words: theoretical sociology, social work, community.

\section{Entre la necesidad constatada y la necesidad construida}

El de las "necesidades sociales" es hoy uno de los conceptos clave de carácter sociológico que ha logrado mayor difusión y éxito en el ámbito de la sociología aplicada, llegando a alcanzar un uso común y una aceptación generalizada durante los últimos años. La afirmación de las necesidades socioculturales se basaría en la suptuesta existencia de unos hechos objetivos de carácter sociał y cultural vinculados a exigencias de naturaleza, y que disfrutarían asimismo de una condición invariable y mensurable. Estos conceptos han venido siendo utilizados de modo recurrente por técnicos y políticos como pretexto de cara a justificar, promover e implementar estudios, propuestas o políticas concretas en toda la diversa gama de intciativas que implica a la sociedad y a la cultura.

A pesar de que los autores clásicos de la sociología habían iniciado una vía de aproximación y asunción de esa idea clave generalmente signada por una razonable prudencia, la práctica de la disciplina ha ido facilitando posteriormente el que se derivase hacia un proceso de reificación favorecido por la consolidación de posturas rutinarias y acríticas proclives al uso fetichizado de este concepto. El modo que ha tenido de manifestarse en el discurso práctico la culminación de esta arraigada hipótesis teórica nos ha inducido a rastrear en el curso del devenir del pensamiento sociológico un tema como éste que en cualquier caso, consideramos, puede seguir hallándose abierto aún hoy a posibles replantcamienros.

Varias son las líneas que trazan el camino que va desde la detección rousseauniana de la necesidad natural a su más sólida cristalización en el discurso antropológico, en el psicosocial, y aún como veremos más adelante, en una relariva asunción de esta apoyatura conceptual por parte de la sociología funcionalista. En el ámbito de la antropología va a ser Bronislaw Malinowski, el antropólogo inglés de origen polaco, quien asuma la labor de radicalizar algunos elementos del funcionalismo con vistas a buscar raíces de necesidad en el modo de producirse los hechos sociales y culturales. En su opinión, la transparencia de los hechos sociales emerge justamente cuando éstos se adecúan y responden a las necesidades orgánicas del hombre, a las emociones y a los medios prácticos de satisfacer esas emociones (B. Malinowski, 1970: 70-74). Las necesidades básicas serían, en su opinión, aquelias condiciones ambientales y biológicas que deben cumplirse para la supervivencia del individuo y el grupo, considera Malinowski este concepto como un recurso seminal preciso para realizar una primera aproximación al conocimiento de la conducta humana organizada. Este autor va a concretar el tránsito entre lo naturał y lo cultu- 
ral, a nivel de necesidades, en un esquema alternativo que situará en polos distintos los elementos respectivos a las necesidades básicas y a unos hipotéticos concomitantes culturales derivados de éstos.

Este esquema incluiría entre las necesidades básicas a las de metabolismo, reproducción, bienestar corporal, seguridad, movimiento, crecimiento y salud. En el otro extremo y como derivación de los anteriores concretaría concomitantes culturales tales como: abasto, parentesco, abrigo, protección, actividades, ejercitación e higiene. Llegado a este punto, y a través de una particular e inercial analogía, consumará su propuesta a través de una discutible elección consistente en erigir un nuevo tipo de necesidades culturales (Malinowski, 1970, p. 106, 119 y 127) que le permitirán abogar por el reconocimiento del poder prescriptivo y normativo del imperativo cultural consolidado. En el trayecto recorrido por nuestro autor vemos como éste va a optar por radicalizar un concepto como el de necesidad y hacerlo extensible al ámbito cultural sin percatarse de los riesgos fixistas y reificadores implfcitos en una tal decisión.

Como ejemplo de la proclividad de la psicología social por la aceptación del recurso a la tesis de las necesidades, puede servirnos de referencia paradigmática la propuesta de Maslow por su amplitud así como por su nivel de concreción al especificar este autor varios tipos de necesidades, precisando entre ellas: la necesidad fisiológica y existencial, la necesidad de seguridad, la necesidad de pertenencia y de amor, la necesidad de respeto y la necesidad, en fin, de autorrealización (Maslow, 1968).

Por supuesto la sociologia tampoco se había mantenido ajena a una aparente solución como la del recurso a la "necesidad" que semejaba poder resolver problemas teóricos diversos. Más aún habría que indicar que el discurso elaborado al respecto por Malinowski habría radicalizado algunas propuestas teóricas que se hallaban latentes de manera más genérica y anclar en el pensamiento durkheimiano.

En Durkheim podemos rastrear en su apelación a la metáfora del funcionamiento orgánico una de las bases teóricas que servirán de soporte y pretexto para la continuidad de este recurso en manos del funcionalismo (Durkheim, 1982a: 416 y Durkheim, 1982b: 416). En todo caso este autor, en el curso de las primeras páginas introductorias del apartado específico que dedica en "El Suicidion a analizar el caso concreto del suicidio de tipo anómico, elabora una propuesta interpretativa que se distanciará de cualquier esencialismo simple de carácter psicologista o biologista. Para Durkheim la sociedad contaría entre sus atributos con el de poder definir sus propias necesidades. Existirán unas exigencias que le resultarían inherentes y que a la vez serían diferentes de las de los individuos. Parafraseándolo diríamos que los actos que aquellas necesidades nos inspirarian no seguirían necesariamente el mismo sentido de nuestras inclinaciones individuales dando lugar éstas, más bien, a privaciones y sacrificios de carácter diverso (Durkheim, 1982b: 370, 262 y s.); pudiendo y debiendo estas coerciones funcionales ejercer sobre el actor social una recomendable influencia moral habida cuenta de que los individuos son proclives a incrementar de manera ilimitada sus exigencias de necesidad. 
Cuando habla de necesidades, Durkheim precisa ciertas claves que nos apuntan la dirección en que se hallan algunos de los tipos a los que éste se refiere, así nuestro autor distingue los requerimientos recesarios para que un organismo se mantenga vivo, al tiempo que se pregunta cómo fijar la cantidad de bienestar, de confort y de lujo que puede legítimamente perseguir un ser humano, afirmando que ni en la constitución orgánica, ni en la constitución psicológica del hombre se encuentra nada que marque un límite preciso a tales inclinaciones.

Las necesidades sociales derivadas de las prácticas de consumo y las exigencias morales precisas al funcionamiento de la sociedad deberían, por tanto, hallar una fuente social legítima que las regulase. Esa legitimidad emanaría de una autoridad ante la que todos se inclinasen. $Y$ acaso esa autoridad únicamente podría ser la sociedad misma, dado que solamente ella tiene la autoridad suficiente para declarar el derecho y marcar a las pasiones el punto más allá del cual éstas no deben ir (Durkheim, 1982b: 264).

La afirmación de la necesidad social como derivación de una exigencia moral apunta en Durkheim hacia una dirección claramente democrática y de vocación contingente, aproximándose en virtud de ello, y merced a un peculiar bucle, hacia unas líneas propositivas que no resultan contrarias a aquellas a las que nos abriremos a lo largo de las últimas páginas de este artículo. En este sentido afirma Durkheim (1982d: 15): "La necesidad con la que las categorias se nos imponen no es efecto de simples costumbres cuyo yugo podríamos sacudir esforzándonos un poco; no es por lo demás una necesidad física o metafísica, ya que las categorías cambian en razón de tiempo y lugar, es un tipo particular de necesidad moral que es a la vida intelectual lo que la obligación moral es a la voluntad». El acuerdo entre los hombres sería la condición precisa para establecer esas ideas marco. Su poder regulador tajante y perentorio emanaría de su origen concertado (Durkheim, 1982d: 343).

De esta manera, la moral, tras ser interiorizada como norma reguladora, pasaría a actuar a modo de soporte ético clave para fundamentar un modelo conductual que pudiese guiar las lógicas de los actores sociales concretos, siendo este el motivo en base al cual Durkheim va a considerar que el ciudadano "si es respetuoso de la regla y dócil a la autoridad colectiva, es decir, si tiene una sana constitución moral, siente que no está bien exigix más" (Durkheim, 1982b: 266). Estas ideas resumen en nuestra opinión los ejes fundamentales sobre los cuales gira y se fundamenta el pensamiento durkheimiano en lo relativo a la cuestión de las necesidades '.

1. Quizás convenga reseñas aqui sumariamente que en el pensamiento de este autor hallamos diversas aperturas de enfoque de solido fusre teórico que se discancian del habitual riesgo de reduccionismo implícito a algunas de las propuestas acerca de las necesidades aqui reseñadas. En este sentido remirimos al lector a una lectura a fondo de las citadas páginas de "El suicidion; asi como de Durkhcim, 1982d: 393 y 395: «Un espiritu culto prefiere no vivir antes que renunciar a los gozos de la inteligencia. Incluso desde el mero punto de vista material, 
En el ámbito de la teoría sociológica va a ser George Simmel el que apunte en una dirección que hasta ese momento se había visto relativamente relegada del horizonte teórico durkheimiano. Nos referimos en concreto a su disponibilidad para estimar y reflexionar, al nivel de análisis microsociológico, acerca de los mecanismos reguladores de los sistemas de necesidades levantando, en virtud de ello, acta de la voracidad consumista que en ese momento empezaba a evidenciarse en el sistema capitalista, el cual -en palabras de Simmel (1986: 126, 304 y 59; 1976: 576-577) — procuratía adivinar los deseos inexpresados o inconscientes del consumidor, sugiriendo o habituando a éste a otros que antes no tenía. Aunque, en su opinión, esta habilidad de la industria no impediría que los consumidores pudiesen influir e incluso reorientar, al menos en parte, el proceso productivo. Redunda en esta idea Simmel al afirmar, en un capítulo dedicado a analizar el fenómeno de la competencia, que la tensión antagónica en la que un competidor se halla frente a los demás competidores, afina en el comerciante la sensibilidad para percibir las inclinaciones del público y llega a dotarle de una especie de instinto adivinatorio para adelantarse a las mutaciones inminentes de sus gustos, modas e intereses ${ }^{2}$.

Una realidad teórica, la de las necesidades, que al fraguar en hipótesis expuestas a variación como las planteadas por Vilfredo Pareto; o en la forma de juicios condicionales de necesidad, en la opinión de Max Weber (Pareto, 1980: 9; Weber, 1984: 33; Weber, 1985: 153 y 26), ha favorecido en gran medida el uso de nociones más abiertas entre las cuales conceptos como el de necesidad pasan a asumir en su caso una entidad meramente adjetiva e instrumental como un medio de apoyo útil para el planteamiento de hipótesis analíticas concretas, puntuales y de vocación limitada y contingente.

La vinculación entre necesidad y sistema apuntada por Durkheirm mantendrá globalmente su vigencia en el esquema Parsoniano (Parsons, 1951: 42), mientras que en la escuela francesa Maurice Halbwachs, aún preservando una considerable dosis de rigidez y sin plantearse inicialmente rebatir los presupuestos esencialistas de carácter psicológico (Halbwachs, 1950a: $137 \mathrm{y}$ 166; Halbwachs, 1950b: 121), tenderá a aceptar diferentes relativizaciones a las que estaría sujeta la jerarquía de las necesidades y entre las cuales resalta su progresiva decantación por dejar de hacer hincapié exclusivo en los aspectos orgánicos funcionales para aplicarse en un enfoque de tipo culturalista que le permitiese captar con mayor claridad el carácrer relativo y abierto de éstas.

todo aquello que va más allá de lo estrictamente necesario se escapa de toda determinación. El standard of life, la muestra típica de la existencia, como dicen los ingleses, el minimo por debajo del cual nos parece que no es aceptable descender, varía infinitamente según las condiciones, los ambientes y las circunstancias" (Durkheim, 1976: 70).

2. Aprovechemos para constatar al respecto la mayor intuición de Simmel sobre las causas generadoras de las anecesidades de consumo". Durkheim, en relación con este tema, habia afirmado que "Es la demanda la que debe suscitar la oferta; es ella la que debe poner en movimiento roda la maquinarian (Durkheim, 1982c: 170). 
Dentro de la sociología francesa dos autores: Raymond Ledrut y Paul Henry Chombart de Lauwe, y de manera particular el segundo, van a dar continuidad y en cierto modo a potenciar el discurso teórico de las necesidades. El urbanista Raymond Ledrut, en sintonía clara con el funcionalismo, asumirá inicialmente sus propuestas para abrirse a continuación a diversas matizaciones que intentan rehuir los riesgos estáticos y esencializadores que amenazan a esa línea de reflexión teórica ${ }^{3}$.

Desde la sociología quizás haya sido Paul Chombart de Lauwe aquél que con más ahínco se empleó en la tarea de postular una definición de "necesidad", algo que él percibía como un concepto nuclear clave de transcendencia primordial para el desarrollo de la sociología aplicada en la Francia de la posguerra. Su posición puede en gran medida resumirse en un intento por potenciar, trascendiéndolo, un concepto como el de "necesidad", de lábiles ecos psicoantropológicos, en base a otro, el de "aspiración", que resultaba más manejable y cuantificable en manos del sociólogo: "Nosotros consideramos que la noción de necesidad debe ser completada inmediatamente con la noción de aspiración. En una población dada, son precisamente las aspiraciones aquellas que deben ser estudiadas y esto tanto si tienen un carácter manifiesto como latenten (Chombart de Lauwe, 1969: 263).

Las líneas de pensamiento que en la sociología buscan un apoyo más o menos intenso en el recurso al concepto de necesidad no se agotan en la propuesta de compromiso elaborada por Chombart de Lauwe ${ }^{4}$ que, todo hay que decirlo, es en gran medida la que parece segutir triunfando si echamos un vistazo hoy sobre el vigente hábito institucional de encargar «estudios de necesidades» sin plantearse en casi ningún caso, ní instituciones ni empresas de sociología aplicada, el carácter final efectivo, supuesto o construido, de tales necesidades.

En otras direcciones caminó aquella otra corriente que buscó apoyo en un discurso de raíz marxista (Heller, 1978: 31 y s.) $)^{5}$. Desde esta perspectiva quizás sea el trabajo de Agnes Heller acerca de las necesidades aquél que mejor ejemplifica esta línea y que, como en momentos sucediera a Chombart de Lauwe, se regala en la enumeración prolija de los, a su entender, distintos tipos de necesidades que resultan discernibles desde un universo que dice contar

3. "La organización del espacio social en unidades colectivas de diversos niveles, coordinadas y jerarquizadas, se presenta como condicion consrante del orden y el funcionamiento que convienen a una sociedad urbanas [...]. "La organización urbana [...] de ninguna manera puede reducirse a un sistema fijo. La completa racionalidad, la racionalidad orgánica, no cierra el paso, permite que el futuro intervenga, lo introduce en el presente. La ciudad no es un instrumento hecho de una vez por todas con vistas a una meta determinada. El ordenamiento utbano es una prácrica colectiva del devenirn (Ledrut, 1974: 263 y 269).

4. En opinión de Jesús Leal la postura de Chombart adolece de un ostensible riesgo al resulear ésta proclive a la conversión del concepto de necesidad-aspiración en un factor omnicompresivo sobre el que giraría toda la estructura de la sociedad (J. Leal y optros, 1988: 23).

5. Habria que referirse aqui a algunas reflexiones teóricas que han hecho una inusual referencia a parentescos entre marxismo y funcionalismo o lo que es parecido a ciertas proclividades funcionalistas del marxismo (Crozier y otros, 1977: 237 y Elsrer, 1990: 57 y s.). 
con su principal fuente de inspiración en la obra de Carlos Marx. Heller se asienta en primer lugar en la afirmación de la existencia de unas unecesidades naturales" que en su opinión "se refieren al mero mantenimiento de la vida humana (autoconservación) y son "naturalmente necesarias" simplemente porque sin su satisfacción el hombre no puede conservarse como ser natural". Desde estas supuestas "necesidades naturales" su discurso se enzarzará afanosamente en desplegar todo un esfuerzo de intenso gradiente retórico que la conducirá a afirmar la existencia a su lado de "necesidades necesarias", aquéllas surgidas históricamente y no dirigidas a la mera supervivencia, "necesidades libres" de carácter individual y espiritual, Ilamadas a germinar con preferencia en el "Reino de la libertad". Junto a éstas, afirma Heller, existirán también unas "necesidades radicales" que estarían llamadas, según ella, a acabar con el capitalismo y que han disfrutado como concepto de un cierto eco y reconocimiento en la última literatura sociológica de carácter crítico.

A todo este laborioso despliegue se le opuso, entre nosotros, actuando como intérprete de la obra de Marx, el filósofo Felipe Marzoa, negando pertinencia a cualquier discurso teótico que convirtiese en antropológica la hipotética asunción marxista de las necesidades, "según un sentido de la palabra "necesidad" - afirma Marzoa - ninguna necesidad es necesaria; todas son "libres" y "espirituales" $y$, según el otro sentido, las necesidades lo son porqute son necesarias, pero no en un sentido antropolb́gico, sino en un sentido económico estructural». En opinión de Marzoa sí resulta, sin embargo, sintomática la disolución del concepto que lleva a cabo Marx a través de una de aquellas expresiones a las que más se ha recurrido para resumir y explicar su pensamiento, "sí es relevante - nos dice-- el hecho de que la fórmula "A cada uno según sus necesidades" constituye la autoanulación del concepto mismo de necesidad". De ahí, considera Marzoa, que los conceptos de necesidad no aparezcan en la obra de Marx como la semilla de una tesis antropológica ambiciosa, sino que más bien "lo que importa de ellos no es su contenido, sino una cierta función que tienen en el sistema" 6 .

Si en el marxismo ha buscado inspiración una corriente afirmadora del discurso de las necesidades en el ámbito del marxismo de vocación crítica, también hallarán acomodo autores como algunos de los ensayistas de la Escuela de Frankfurt, entre los cuales tanto Adorno y Horkheimer como Herbert Marcuse (Adorno, 1987; Marcuse, 1981) recurrirán al manejo de ese concepto. De manera particular se detendrá en ello este último autor, quien lo hará a partir de un discurso taxonómico y crítico dirigido a cuestionar aquellas fal-

6. Sobre este tema como ya vimos se habría expresado Marx previamente, en línea con la interpreración de Marzoa, en su Miseria de la Filosofia, al criticar el antropologismo que él percibia en la valoración que Proudhom realizaba de la "competencia" como emanación de una supuesta necesidad humana de zal; (F. Martinez Marzoa, 1983: 171-177). Quede dicho aquí, y tal y como nos precisa Leal, que la aportación del marxismo ha resultado clave al insiscir en plantear ulas diferencias que se dan en las neccsidades según la distinta inserción en el aparato productivo; es decir, según la pertenencia a clases sociales diferenresn (I. Leal y otros, 1988: 24). 
sas necesidades que en su opinión servirían de soporte y pretexto al funcionamiento general del sistema capitalista occidental.

En una aproximación crítica a los Estados Unidos de inicios de los ańos cincuenta, Marcuse, tratando sobre el tema de las necesidades sociales, constatará inicialmente la existencia de una línea divisoria establecible entre necesidades básicas y falsas necesidades. Esa inicial ordenación que le conducirá a cuestionar el universo de las necesidades y satisfacciones en clave de simple verdad o mentira logrará hacerla compatible con la afirmación y el reconocimiento de la historicidad sustancial de esos asertos (Marcuse, 1981: 35, 36, 39 y 46).

Tras su ambigta reducción de lo natural a lo histórico, habida cuenta de su no renuncia a la propuesta dicotómica inicialmente establecida entre necesidades básicas y falsas, Marcuse se dirigirá hacia el centro de sus preocupaciones teóricas con su discurso crírico acerca de los modos manipuladores en base a los cuales - según él一 el sistema resuelve su relación con las necesidades. El sistema poseería en este sentido la virtualidad de hacer de valores necesidades, creando de esa manera necesidades represivas. Ese proceso conversor se produciŕa merced a una dinámica sibilina de palo y zanahoria (Marcuse, 1981: 261 y 274), en virtud de la cual el sistema sabría hacer pasar el trigo mezclado con la cizaña.

De esta manera la sociedad industrial (Marcuse, 1981: 39), haciendo de lo superfluo necesidad, lograría ir incrustando el control social como un sutil añadido y en virtud del reconocimiento de este proceso nuestro autor irá eliminando todo margen de maniobra al actor social, el cual se va a ver reducido a un unilateral estatuto de seducido y dominado. Esa situación facilitaría según, su posición, la reproducción fluida del sistema. Toda la gran máquina industrial y consumista no tendría dificultad excesiva en garantizar de ese modo su propia continuidad. Frente a este bloqueo aparente, Marcuse postula finalmente una frágil, paradójica y poco convincente hipótesis de resolución fundamentada precisamente en el recurso a una supuesta capacidad de respuesta del propio actor social (Marcuse, 1981: 274) para poder erigirse en protagonista de una redefinición cualitativa de las actuales necesidades sociales.

No obstante cabría acaso decir, Ilegados a este punto, que más allá de las críticas a la tendenciosidad estructural y a las fragilidades que presenta el concepto socioantropológico de necesidad, éste ha logrado alcanzar y disfrutar de un considerable eco y presencia entre la literatura socioeconómica, la cual lo ha utilizado y manejado a menudo como un argumento tensionador y reproductor de flujos sociales de signo diverso, to que ha conducido con frecuencia a que la crítica a un concepto con presencia en el área de influencia del marxismo se haya confundido y mezclado con su posible pertenencia al pensamiento fundador de Marx ${ }^{7}$.

7. Véase en este sentido: El marxismo, "asumi 6 , sin reducirla, ta idea de necesidad, secularizándola en el concepto económico de penuria, Qué es la idea de "necesidad natural" sino una idea moral dictada por la economía polícica, versión ética y filosófica de esa mala naturaleza de la que vimos hasta qué punto forma sisrema con el postulado arbitrario de lo económico. En el espejo de lo económico la Naturaleza nos mira, en efecto, con los ojos de la necesidad" (Baudrillard, 1983: 59). 
El recurso al concepto de necesidad ha seguido hallando defensores en territorios distintos, así como a partir de intenciones también diversas. $Y$ esto tanto desde posiciones críticas respecto del sistema ${ }^{8}$ como desde aquellos otros que se reafirman en una rutina acrítica reproductora de la sociedad. En general aquellos que han reflexionado sobre el urbanismo han tendido con naturalidad a acudir al concepto de necesidad como a uno de tantos recursos utilizables para aprehender las transformaciones producidas en la sociedad del moderno bienestar.

Unas necesidades que al ser cubiertas tienden a dejar un espacio disponible vacío para que otras nuevas las puedan sustituir (Ledrut, 1974: 189). Una ciudad eje del consumo, que se erige en medio informativo productor de unas necesidades que con urgida fluidez ella misma se apresta a satisfacer (Laborit, 1973: 144). Incluso aquellos que manifiestamente rechazan la hipótesis de la existencia de necesidades de carácter natural o esencial (Fourquet y otros, 1978: 34) se refieren de modo instrumental a conceptos próximos «necesidad ordinaria y cuantitativa» frente a «necesidades difusas y cualitativas». Necesidades todas ellas que buscarían acomodo y realización en un flujo continuado generador de espacios equipamentales.

En este contexto el carácter retórico de las necesidades más sutiles ha ido haciéndose evidente para sociólogos y urbanistas al irse constatando en diversos trabajos de investigación como difícilmente podía resultar discernible cualquier consolidación social y conceptual de necesidades que fuesen más allá de ciertos servicios mínimos: «con la excepción de las tiendas de comestibles y quizás de las escuelas primarias, son muy pocas las instalaciones cuya cercanía se considera necesaria"?

Las necesidades socioculturales resultan mucho más dificiles de vislumbrar (OCDE, 1989: 176), aunque parecen tender a hacerse evidentes a medida que se resuelven aquéllas de carácter más primario (De Baecque, 1967: 11; Arent, 1972: 269). De todos modos, el concepto de necesidad ha tendido en general, y de modo genuino, a funcionar como un recurso, como un constructo intelectual, resulzado de una situación dada y emanado desde un proyecto normativo (Coenen, 1970: 29). Proyecto normativo que hallaba aliados tanto en

8. "Il faudrair élaborer une riche théorie des besoins fondamentaux, ce qui serait très complexe certes, celle-ci ne saurait égaler ni la complexité de la vie humaine ni celle de la realité sociale, roures deux infiniment variées. Et ce qui semble à certains un vice intrinsèque de l'érude des besoins fondamentaux peut devenir une verru: elie n'est pas seulement complexe, elle est chaotique. Et pourquoi pas? Peut-ĉtre devrait-elle rester chaotique pour servir de garde-fou contre une simplicité qui pouvrair devenir trop facilement la base de manipulations bureaucratiques /capiralistes / intellectuels!». (Spizt, 1980: 127). Sirvanos esta cita de ejemplo de lo que descamos decir.

9. Keller, 1975: 172, y esto no sólo en el caso anglosajón, asi Ledrut (1974). en su estudio sobre la ciudad de Toulouse, nos dice en p. 190: "Podemos afrmar que las necesidades prioritarias se refieren a los comercios de primera necesidad -en particular a los que expenden alimencos-, así como a los establecimientos escolares de enseñanza primarian. 
el sector empresaria ${ }^{10}$, el cual se afanaba por ampliar constantemente los productos de consumo circulantes en el mercado dirigidos a satisfacer necesidades, como en el caso de unos servicios y equipamientos que habiendo sido erigidos con la voluntad de cubrir unas afirmadas necesidades sociales y culturales iban a ver como eran parasitados por toda una densa propuesta de vocación normalizadora y modelizadora (Roch, 1985: 24). Quede dicho aquí también que si bien esta propuesta voluntarista y moralizadora, a menudo promovida desde el estado, se había hecho inicialmente eco de expectativas emanadas desde la comunidad, ella misma no iba a mantener ningún tipo de vínculo con la comunidad que fuese mucho más lejos de unas simples relaciones pasivas y clientelares de carácter episódico y coyuntural. De este modo, la estrategia dirigida a captar necesidades y a traducirlas en equipamientos úriles para orientar la producción de un ciudadano medio tipo, ha resultado ser uno más de los pilares en los que se ha inspirado la génesis y la difusión de los equipamientos sociales y culturales.

La afirmación de que resulta imposible medir a todos los ciudadanos por un idéntico rasero inductor de necesidades medias (Foucault, 1983:53) se encamina en la misma dirección en que lo hace el hecho de que la exigencia de definir y fraguar necesidades resulta una condición prioritariamente útil al mantenimiento del propio sistema. Este tipo de afirmaciones nos permiten constatar la fragilidad teórica de aquellas propuestas que pretenden instaurar en lo social la ley consolidada de lo natural y necesario precisamente allí donde suele habitar lo contingente y negociable $e^{11}$.

Uno de los territorios en donde el concepto de necesidad natural, básica o fundamental más se habría recreado tal vez haya sido en aquel que hacía referencia a la necesidad de alimentarse, biologizándola y olvidándose de que en ella se produce un intenso tráfico de contenidos sociales y culturales (Boltanski, 1982: 50) que no siempre resultan inmediatamente perceptibles. Las virtualidades múltiples y contradictorias que habitan en el rito de alimentarse configuran un ámbito de densa complejidad en el cual la necesidad biológica aparece como un hecho elástico y relativamente acomodable a decisiones y condicionamientos de origen diferente. El consumir alimentos compulsivamente y/o selectivamente como un acto de revancha ante otros consumos imposibles, o incluso el sacrificar los niveles medios de consumo alimentario para así no impedirse el acceso a lujos que permiten ostentar un cierto estatus simbólico. Son todos ellos ejemplos que alejan y matizan la posible creencia en la existencia pura de una jerarquía "natural» de las necesidades (C. Grignon, y otros, 1982: $33 \mathrm{y} \mathrm{s}$.). En el acto de la alimentación lo biológico y lo funcional social entretejen una compleja mailla que muestra como en los actos de consu-

10. Dumazedier, 1988: 221. En esta línea resulta relevante la llamada de atención de Gómez de Liaño (1989: 239) acerca de los riesgos totalitarios que pueden estar latentes en el modelo consumista occidental.

11. En esre rema el acuerdo reórico resulta razonablemente amplio: $R$ Boudon, 1981: 171 y 223, asimismo, Bourdieu, 1987:25. 
mo nunca son sólamente valores de uso los que circulan. Al consumir, el ciudadano moldea también entre sus manos unos valores que son útiles a su propia definición social.

La conveniencia de establecer este tipo de matizaciones no es algo reciente en el pensamiento sociológico, Thorstein Veblen en su conocido estudio acerca de la clase ociosa ya nos apercibla acerca de que el supuesto móvil de la necesidad física, incluso para las clases carentes de medios, no resulta tan claro ni preferente como a veces se supone, sucediendo en ocasiones que se privilegie el gasto ostensible y honorifico al tiempo que se relega aquél vinculado a necesidades "inferiores" de bienestar ffsico o de sustento. Veblen llega a afirmar que no existe clase o pals que se haya inclinado ante la presion de la necesidad flsica de modo tan absoluto que haya llegado a negarse totalmente a sí mismo la satisfacción de necesidades superiores o espirituales (Veblen, 1971: 34, 108 y 109).

Un caso extremadamente significativo de consumo de signos ostentativos ajeno a las necesidades básicas acaso lo represente aquél que dirigido al mantenimiento de un cierto estatus honorffico resultaba necesario para el disfrute de un determinado grado de poder e influencia política $y$ aún económica ${ }^{12}$. Esfuerzo que, como sabemos, en muchos casos arruinaba a sus cultivadores, generando precisamente la pérdida de aquéllo que se intentaba preservar (Sombart, 1979: 63 y s.).

Una práctica ésta que habiendo sido frecuentada por aquellos que ocupan los espacios más privilegiados dentro de la jerarquáa social les ha conducido a esforzarse en traducir lo contingente, es decir, el más o menos azaroso disfrute de una posición de privilegio, en la cristalización de una posición que se deseaba justificar en base a una diferencia de carácter natural (Mills, 1969: 18).

Una sociedad, la nuestra, en la que la infancia actúa como ámbito consolidador de evocaciones de lo contingente (Berger y otros, 1979: 171). Un contexto social, aquel en el que vivimos, en el cual los "actos de institución" tienden a instaurarse en la forma de categorizaciones solemnes (Bourdieu, 1985: 81). Unas sociedades en el seno de las cuales la lucha por definir la verdad (Bourdieu, 1987: 114 y s.) suele encubrir una lucha más profunda en la cual distintos grupos se han afanado en procurar confundir aquello que se considera objetivamente útil con aquello que resulta útil para ellos mismos.

En los linderos de este tipo de estrategias los intelectuales, a menudo intentando moverse en las arenas del mal menor, no han renunciado del todo a recurrir al têrmino "necesidad", acaso en una inflexión que tiene más que ver con su cómoda instrumentación retórica que con la capacidad de convicción (Diem, 1978: 95) que el propio concepto es capaz de provocar. Aquf parece cumplirse la máxima de Elster de que en general el recurso al estereotipo propende a facilitar la vida y aportarnos paz al espiritu (Elster, 1988: 147-7). Acaso por esa via un concepto como el de necesidad, afecto al universalismo abstrac-

12. "El honor social (prestigio) puede constituir $y$ ha conscituido con gran frecuencia la base hasta del mismo poder de tipo económicon (Weber, 1969: 683). 
to y que ctenta con hondas raíces funcionalistas, se vea compelido a sobreactuar, merced a un flujo de inercias y connivencias, como un oportuno instrumento de regulación en un contexto de relaciones sociales mediatizadas.

Entre nosotros aquellos escasos autores que como Jesús Leal se han ocupado del uso y abuso conceptual del término unecesidad" en dirección a la promoción equipamental, han solido dejar constancia de su rechazo de los enfoques esencialistas (Leal, 1979: 11-2; Lles, 1980: 19) optando en su caso por una aproximación que, tras fundamentarse inicialmente en una percepción de la necesidad como un hecho vinculado a las exigencias socioeconómicas de la reposición de la fuerza de trabajo, ha derivado hacia una lectura más compleja inspirada en el objetivo de remarcar la transcendencia de los diversos aspectos sociológicos y participativos que concurren en este concepto (Leal y otros, 1988: 220, 242 y s.).

Por su parte Michel Pinçon ${ }^{13}$ en un análisis del concepto de necesidad que tendía a aproximarlo al campo teórico de la sociología se había mostrado también claramente contrario a aquellos enfoques reduccionistas que limitasen la interpretación de ese fenómeno a las exigencias de la reproducción, incluso ampliada, de la "fuerza de trabajo". Considera este autor que esa perspectiva no valora suficientemente la dimensión subjetiva de esas necesidades ni la vivencialización de unas prácticas que permanecen cargadas de todo el sentido social que le confieren las relaciones sociales en las cuales éstas se inscriben. En su opinión la posible sustitución del concepto de "habitus" ${ }^{14}$ elaborado por Bourdieu, en lugar del de "necesidad", permitiría analizar las prácticas de consumo evitando los escollos del subjetivismo y del objetivismo sobre los cuales suele fragmentarse la sociología de las necesidades.

13. Pinçon, 1978:16,23, 31 y 45. Habria que decir también aquí que Martínez Pardo (1985: 4-8) integro entre nosorros algunas de las propuestas de Pinçon en un ensayo dirigido a reenfocar este ámbito teótico.

14. "Ce que la staristique enregistre sous la forme de systèmes de besoins n'est autre chose que la cohérence des choix d'un habitus [...] si tout porte a croire en l'éxistence d'une relation directe entre les revenus et la consommation, c'est que le goutt est presque toujours le produit de conditions économiques identiques à celles dans lesquelles il fonctionne, en sorte que l'on peut imputer au revenu une efficaciré causal qu'il n'exerce qu'en associarion avec l'habitus qu'il a produir». Bordieu, 1979: 437: «Etane le produir de l'incorporation de la nécessiré, l'habirus, nécessiré faice vertu, produit des stratégies qui, bien qu'elles ne soient pas le produit d'une visée consciente de fins explicitement posées sur la base d'une connaissance adéquate des conditions objectives, ni d'une détermination mécanique par des causes, se trouvent être objectivement ajustées à la situation".

Bourdieu, 1987: 21. Resulta pertinente constatar aqui que algunos autores clásicos, antes que Bourdieu, habían avanzado hacia esra hipótesis al aproximar necesidad y hábito. "Desde los primeros actos por los cuales el hombre trata de satisfacer necesidades, cada acto se explica por sí mismo y no busca más que la satisfacción inmediata. De necesidades recurrentes nacen hábitos para el individuo y costumbres para el grupo, pero esos resultados son consecuencias que nunca son conscientes ni previstas o buscadas" (Summer, 1906: 3); asimismo: "En el dominio de cada necesidad especifica se desarrollan ciertos hábitos, $y$, dentro de una organización cultural, estos hábitos encuentran satisfaciones rutinariamente organizadasn (Malinowski, 1970: 102). 
El riesgo de verificación infrerente al concepto de necesidad resultaría conjurado con el recurso alternativo a una noción como la de habitus que aleja el condicionamiento absorbente de una hipotética lógica derivada de manera inevitable y exclusiva del modo de producción.

Necesidades y prácticas que pueden ser producto de las ideologías del consumo al uso, germinadas bien desde la sociología "espontánea" de las prácticas consumistas, bien desde unas relaciones capitalistas empeñadas en la procura de la orientación más favorable a la realización del mayor beneficio posible. Un concepto, el de habitus, que resultaría particularmente poderoso y eficaz para eludir el "terrorismo" coercitivo de la estructura al reintroducir en el análisis la vivencia subjetiva (que se expresa en términos de selección y de gusto...), en tanto que modalidad de ejercitación del habitus en una coyuntura y contexto concreto. Desde esta percepción redefinida de las necesidades, un concepto, emparentado con el de "Efecto Mateo" (Merton, 1977), el de "Silencio de las necesidades", intenta mostrar un estado de vacío que tendría que ver con aquellas actitudes próximas en nuestro caso a los flujos de autoequipamentación y que afectarín a aquellos a los cuales un particular "principio de realidad", frenando el desarrollo de su habitus, compelería a contentarse con aquello que se posee y a no aventurarse en orros vuelos. "Silencio de las necesidades" que aquejaría de modo particular a algunos sectores laborales o sociales aislados que hallarían en las organizaciones sociales y de clase, así como en las agencias de desarrollo, a los actores privilegiados encargados de hacer "alumbrar" otras necesidades nuevas; es decir, serían los encargados de hacer tomar conciencia a esos sectores populares de sus necesidades potenciales o nuevas necesidades más allá del silencio, la desafección y la renuncia (Pinçon, 1978: 62 y s.).

Concluyendo, por tanto, el cambio de perspectiva que va del hacer hincapié en el lábil concepto de "necesidad" a hacerlo en el de "habitus", parece permitir aproximarnos a un enfoque superador de una discutible taxonomía de las necesidades básicas, abriéndonos a otra forma de ver las cosas centrada más bien en el esfuerzo por alcanzar una distribución más igualitaria de la riqueza material, para la cual las inversiones de carácter colectivo se opondrían a aquéllas de carácter privado e industrial. Asimismo, la toma en consideración del "habitus" permire evitar su congelación en formas estandarizadas caras al universalismo abstracto, así como el poder asumir y actuar desde aquellos contextos sociales y culturales en los cuales tienen lugar diferentes tipos de iniciativas ${ }^{15}$ tales como la producción e implantación de equipamientos culturales.

Muy probablemente la introducción de un sesgo en las ciencias sociales que tienda a pensar en las necesidades sociales desde el habitus, y no desde una asunción de carácter psicobiológico y esencialista previo e independiente de los condicionamientos sociales, no se halla exenta de dificultades que pue-

15. "Una sugestion ya mencionada cra la de enfrentarse con los factores especificos de cada situación, y no con làs necesidades básicas, analizando las imágenes, las funciones latentes y los aspectos simbólicos de cada contexto dadon (Rapoport, 1978: 99). 
dan llevarnos a vagar por la indeterminación inherente al relativismo cultural $e$ incluso por la dificilmente eludible dificultad de establecer como homológica una relación, la de necesidad y habitus, all donde en gran medida lo que tiene lugat es una interseccion o un juego de causas y efectos. Con frecuencia no todo lo definido como necesidad social es reducible o equivalente al habitus, del mismo modo que el habitus en muchos casos ha sido inducido por lo que algunos consideraron en un momento determinado como necesidad previa prefiguradora. Quizás aquí el campo de la medicina social y la salud podrlan, mejor que otros, aportar ejemplos clarificadores. De igual manera, el hecho de que la necesidad se haya manifestado como un constructo conceptual mientras que el habitus emerge como instrumento que capta y resume prácticas sociales efectivas, da lugar a que contenidos y funciones de uno y otro no siempre se adecúen.

Es muy posible que tal vez - y entre otras- por esta causa esta alternativa pueda no resultar eficaz del todo para evacuar definitivamente un concepto, el de necesidad social, que recubre realidades y situaciones diversas dificilmente reducibles a otra única noción. No obstante, la aproximación de necesidad y habitus está llamada a facilitar la disolución de la arbitrariedad y la vocación esencialista del primero de estos conceptos.

Si en ocasiones desde la supuesta necesidad se ha provocado el cambio de habitus, en otros múltiples casos el trayecto recorrido ha sido precisamente el contrario y desde un habitus que encontraba dificultades para concretarse socialmente, el equipamiento ha sido convocado como catalizador y precipitado que resolviese un conjunto de expectativas heterogéneas de movilidad, de reivindicaciones socioculturales y aún también de concesiones sociopolíticas.

Aunque para una mejor comprensión de estos procesos deberfamos quizás seguir ahondando en todo el tráfico de iniciativas de diverso signo merced a las cuales diferentes actores sociales como el estado, sus políticos, técnicos y especialistas varios, actuando a menudo desde el silencio de las necesidades y en comunidades en las que el habitus se define prioritariamente por sus precariedades o por la colonización de las prácticas, logran servirse de las necesidades como de un pretexto retórico que a pesar de mostrar una autoconvicción profética no hace sino abrevar en la consolidada heterogeneidad jerárquica de los estilos de vida, normalmente recurriendo a un modesto horizonte que pone el punto de mira de la redención popular en el objezivo de la imitación del habitus de las clases medias. Tal es asl que este tipo de prácticas tenderán a una promoción de iniciativas y modelos equipamentales que, lejos de potenciar el habitus existente y sus virtualidades, aquello que generalmente han procurado ha sido en una gran medida congelarlo, en virtud de la promoción de prácticas populistas, cuando no negarlo y sustituirlo desde el peso y prestigio de la cultura ilustrada.

En la relativamente larga tradición de la sociologla de la comunidad y el urbanismo se ha puesto de modo recurrente en evidencia la capacidad inherente al equipamiento social y cultural para poder producir flujos favorecedores de la socialidad que actuarian como soportes para la constitución de 
territorios-comunidad ${ }^{16}$. A través de este peculiar dinamismo la necesidad hecha función apeló a un órgano que surgla en forma de equipamiento y a éste, a su vez, devenido institución, se le supuso inductor de socialidades comunitarias.

Entre bastidores, en la retaguardia de este proceso, unos agentes privilegiados, los planificadores sociales y urbanos, van a erigirse en los directores de una obra de la que se espera que al producir cambios formales posea la fuerza suficiente para hacer evolucionar también aquellas conductas y actitudes de tipo informal que servirfan de soporte a la existencia de comunidades (Festinger y otros, 1950: 50 y s.; Kuper, 1953: 165 y s.).

Planificar y producir un topos que, reconduciéndola y dimensionándola domestique a la utopla, ha configurado una tendencia y una práctica que, a pesar de haber experimentado consecutivos auges y declives, se ha mantenido siempre próxima a la vocación de algunas áreas prácticas de las ciencias sociales. Utopía y planificación han conjugado una de las formas posibles bajo las cuales se ha producido en nuestra historia moderna el diálogo entre lo informal y lo formal ${ }^{17}$.

A lo largo de este proceso semeja ir consolidándose un ciclo que va a actuar desde raíces germinadas en el mito de unas necesidades sociales preexistentes, hacia la reconducción de los impulsos de deseo y utopía en dirección al plano y la cifra del planificador. El desactivar, reconducir y planificar para inducir, parece haber acompañado como práctica especifica al despliegue de las sociedades nortefias del presente siglo. Más allá de los esfuerzos que hace el hombre por controlar al hombre, éste a menudo opta renuente por perseverar en el vagabundaje y el absentismo.

Desde el planificador que crea e induce realidad hemos circulado hacia aquel que simplemente levanta acta de una realidad preexistente. De la ilusión de producir lo social se camina hacia la constatación de los limites de la artesanía del Leviathan ${ }^{18}$. El fluido comunitatio suele emerger alli donde los vecinos lo desean y acaso les conviene y no necesariamente all donde el planificador se esfuerza en inducirlo. En territorios anómicos de frfa ausencia urbanistica puede germinar intensa la semilla solidaria, mientras que autosatisfechos, equipados y concluidos barrios norteños languidecen en su tibia pasividad.

16. En esta linea véase West, 1945: 71 y Kuper, 1953: 8, 170 en el mismo sentido "Un uso concentrado y diferenciado de las tiendas, las escuelas, los parques y los cines [...] puede servir para unir a los habitantes entre $s i \mathrm{e}$ indirectamente al atrea a través de la instalaciones locales compartidas" (Keller, 1975: 151); "Les équipements [...] c'est à travers leur présence que certains lieux [...] se constituer en espace geographiques et sociaux identiftables" (Augustin, 1987: 197).

17. "Pour les utopistes, $]_{2}$ création d'une société nouvelle requiert des espaces nouveaux» [...] "On a pu méme confondre utopie et planiftcation, tant le tève des urbanistes rejoint l'image de la ville utopiquen (Clavel, 1986: 215 y 218 ).

18. "Uso concentrado de los servicios locales y fuertes lealtades locales son sólo expresiones de la cohesión de los vecindarios, no sus causasn (Kellet, 1975: 179). 
De tal modo la realidad se ha mostrado remisa a los voluntariosos esfuerzos del planificador que habitualmente su desarrollo y su transformación se ha visto jalonada por una serie de constataciones paradójicas entre las cuales quizás una de las primeras que se nos revelaron y se nos han seguido evidenciando sea aquella de que la solidaridad y la socialidad comunitaria alumbra precisamente alli donde aprieta la escasez de recursos y la distancia limita con su aislamiento (Stacey, 1960: 105; Morris y otros. 1965: 120; Bidart, 1988: 637). Allí donde las demandas insatisfechas son mayores, las dinámicas solidarias y de apoyo mutuo tienden a multiplicarse.

Sucede en este sentido que con frecuencia el equipamiento, declarándose a favor del desarrollo de lo solidario y comunitario, se halla paradójicamente trabajando en una dirección contraria que vacía de contenidos a algunos de los factores motivadores tradicionales de la socialidad local, cuando no de la propia familia (Fourquet y otros, 1978). Una ciudad desvirtuada que en la medida en que se diluye en la jungla narcisa del asfalto genera una proyección reificada con su progresiva demanda de viviendas secundarias como evocación de un mundo rural perdido. Un mundo rural aftorado el cual se verá llamado aqú a funcionar como nicho de repliegue producido para conjuxar una ausencia (Debord, 1976: 123).

El movimiento subyacente a este proceso parece culminar una paradoja que había sido puesta ya en evidencia por la lúcida intuición fundadora de Maciver cuando estimaba que a las comunidades para poder salvarse no les quedaba más remedio que desaparecer (Maciver, 1917: 211). Acaso una desaparición que estaba llamada a disfrutar de una reaparición con ropajes y contenidos diferentes. La intuición barthesiana de que los delirios de hoy son a veces las verdades de mañana ${ }^{19}$ no se halla muy distante de la constatación de W. I. Thomas cuando afirmaba que si la gente define una situación como real ésta será real en sus efectos.

En los últimos años y desde perspectivas teóricas no necesariamente coincidentes, se ha venido llamando la atención sobre la capacidad de los planteamientos previos tcóricos e ideológicos para producir e inducir realidad. Unos proyectos que al fin hijos de la cultura, valores y poderes que le dan soporte devienen útiles para canalizar socialmente las acrividades, sirviendo así a la institucionalización y dando lugar a través de ese recorrido a una continuada construcción social de lo real ${ }^{20}$.

Aunque sin detenerse en esta vía teórica con excesivo detenimiento, Pierre Bourdieu (Bourdieu, 1987: 29) capta con precisión y asume, aunque sin darle un valor absoluto, la verdad esencial de esa idea: "Yo llego a decir que son las

19. Barthes, 1981: 36 «QQué cambio humano no ha sido formulado simbólicamente a través de una ficción? [...] No estamos hechos de reperición ni de formalismo, sino tejidos de la materia misma de nuestros sueños". (Duvignaud, 1990: 36).

20. En este sentido es paradigmática la conocida obra de Berger y Luckmann (1979); heredera del trabajo previo pionero de reajuste de los aportes fenomenológicos realizado por Schucz desde la Sociologia: A. Schutz, 1974a y 1974b. 
estructuras simbólicas las que producen las estructuras sociales [...] lo que sí es seguro es que, dentro de ciertos límites, las estructuras simbólicas tienen un poder extraordinario de constitución [...] que hemos en gran medida subestimado". Llegando Bourdieu a afirmar, al preguntarse acerca de este poder, "si acaso las estructuras sociales de hoy no son las estructuras simbólicas de ayer y si, por ejemplo, la clase tal como la constatamos no es en una cierta medida el producto del "efecto de teoría" ejercido por la obra de Marx. La idea que subyace al efecto de teoría y la afirmación de Berger y Luckman de que "las ideas pueden realizarse en la historia», no parecen caminar a excesiva distancia lógica la una de la otra (Berger y otros, 1979: 163).

Acerca de este tipo de hipótesis la sociología e incluso la pedagogía ${ }^{21}$, habían venido llamando la atención sin que se hubiese producido hasta estos años más recientes una asunción generalizada del potencial prescriptivo del conocimiento. Evidentemente las proposiciones son susceptibles de hilvanar efectos reales, como ya había afirmado W.I. Thomas, en la medida en que sean capaces de conseguir servir de modelo y referencia para los comportamientos sociales (Bateson, 1984: 80). De ahí por lo tanto la importancia que presentan en nuestras sociedades las dinámicas de consenso negociador, así como aquellas de carácter connivente que se generan en torno a las iniciativas y proyectos sociopolíticos y socioculturales.

En ese proceso el sistema social dominante, y más concretamente los estados del bienestar, acabarán por precisar del recurso a las "necesidades" en tanto que inspiración y en tanto que factores desencadenantes también de las políticas culturales (Gaudibert, 1972: 21). En sus entornos las ideologías al uso se encargarán de hacer deseables a los individuos las que en principio resultan ser, fundamentalmente, necesidades del propio sistema (Ibáñez, 1986: 33). Emergiendo así una sociedad que alcanzará su lógica reproductora última no sólo merced a la satisfacroria culminación de la producción y venta de sus mercancias, sino, y ya al filo del cambio de siglo, en la exigencia de producir a esa misma sociedad encargada de adquirirlas (Barel, 1984: 63).

De este modo se produce y reproduce todo un ciclo que, al saber reducir a medidas contables y a objetivos concretos la problemática social y las formas de realización del individuo, consigue generar una dinámica llamada a perdurar como si de un proceso continuo e ilimitado se tratase. Así, se favorece la emergencia de rutinas sistémicas que al ejercer en la depredación de los repliegues utópicos consigan, al fagocitarlos, abrevar ellas mismas en la fuente de la eterna juventud. Teniendo esto lugar además en un contexto social que nunca como hoy disfrutó de la capacidad fulgurante de demandar y producir líneas innovadoras que le permitan intervenir sobre y producir lo social (Augustin, 1987: 183-200).

No obstante, más allá de lo dicho y en la arena de lo social, ni por activa ni por pasiva, resulta todo reducible a los imperativos de lo previamente prescri-

21. Véase en este sentido Merton, 1964: 505 y s. En el caso de la pedagogia, sirva aquí de ejemplo el conocido "Efecto Pigmalión" de Rosenthal. 
to. Los hábitos no sólo son promovidos por decisiones vinculantes, también el medio social es cuenco en el que se aproximan o diversifican los grupos sociales y sus posibles modos de actuar al amparo de sus voluntades (Diem, 1978: 81-82; Gryspeert, 1974: 163).

Los conocidos procesos de complejización sociológica que han caracterizado la evolución de las modernas sociedades norteñas no se han hallado tampoco ausentes de los modos de producirse en ellas la gestión del consenso. Las políticas culturales, y más en particular las de equipamentación sociocultural, pueden en gran medida servir de ejemplificación a esta dinámica ${ }^{22}$.

Si uno de los procesos centrales que han servido de estímulo al mantenimiento y reproducción de nuestra última sociedad moderna ha sido el de la posible autoinserción de los ciudadanos en las dinámicas de movilidad social; la promoción que desce el ámbito de la cultura se ha efectuado de este espacio como recurso laboral ha sido una de las manifestaciones a través de las cuales se ha hecho ostensible y posible esa nueva forma de integración.

En torno a los equipamientos socioculturales, a su demanda y producción, existe en muchos casos el riesgo de que se mantenga y generalice una dinámica clientelar subsidiaria de corporativismos profesionales, y de asociaciones que se limite a concretar demandas en función de las expectativas y predisposiciones de unos políticos locales afectos al ejercicio rutinario del electoralismo populista (Gaullier, 1982: 221). Esta situación contribuiría a generar y a afianzar un sesgado modelo de sociedad gestionaria que actuarla ignorando la delicada y creciente distancia existente hoy entre aquellos que se hallan implicados y que disfrutan de la capacidad de ejercer funciones de control y aquellos otros compelidos a sobrevivir en los márgenes. En este sentido, la actual y progresiva sociedad de tipo dual que vemos avanzar entre nosotros se presenta como un frágil caldo de cultivo abonado para evidenciar tos riesgos de este tipo de escisión.

De manera simultánea, esta sociedad va a ir configurando toda una compleja red que conducirá a la multiplicación consecuente de las formas de dependencia, así como a la congelación y rutinización democrática (Foucault, 1983: 53), pudiendo derivar esta situación de superprotección y de aparente privilegio hacia diversas formas de ineficacia y bloqueo (Baudrillard, 1987: 65). La paranoia nortefia, el usindrome suizo", el temor xenofóbico a la eclosión invasora de un sur precario, parece hallarse ejerciendo hoy en los umbrales de una peculiar decadence acaso llamada a cuestionar algunos de los cimientos sutilmente patriarcales, autoritarios y consumistas que han venido disfrutando de una particular vigencia en la génesis reciente de las actuales sociedades occidentales.

Una vez rebasada ya hoy la propuesta funcionalista ${ }^{23}$, probablemente la única alternativa a una situación como la actual, que en gran medida coarta y

22. Véase Segura Sanz y otros (1988: 88) acerca de la capacidad generadora de empleo de que disfrutan los equipamientos en general.

23. "Hoy día los presupuestos del funcionalismo están culturalmente superados y nadie discute el carácter histórico y socialmente contingente de las necesidades, reconociéndose su 
condiciona la posibilidad democrática de definir necesidades, sea aquélla que circule en dirección a rcplantear los modos habituales de producirse las claves sociales que sirven para concretar en cada momento lo que resulta más conveniente para el bienestar de la comunidad.

Parece claro que en el momento actual las opiniones más autorizadas de entre aquellas que se han aproximado a reflexionar sobre la cuestión de las necesidades han levantado acta del constatado declive - al menos desde una perspectiva sociológica-- de aquel enfoque que habría tendido sesgadamente a privilegiar la autoridad coercitiva y la rigidez de una estructura amparadora basada en la hipotética existencia de un sistema cerrado de necesidades.

Quizás ese progresivo cuestionamiento, en gran medida parajelo a la recuperación del protagonismo de los actores sociales, no le resulte del todo ajeno a una etapa como la actual caracterizada por un repliegue individualista que ha sido germinado, en gran medida, al cobijo de una sociedad en la cual la progresión en los ratios educativos medios de la población y el desarrollo de la capacidad de intervenir activamente en los movimientos sociales ha facilitado la convergencia entre lo expresivo y lo instrumental, al tiempo que ha favorecido también la derivación progresiva hacia esquemas de valores de tipo postmaterialista ${ }^{24}$. Esta particular coyuntura puede hallarse relacionada, tras su aparente atonia, con la simultánea presencia de flujos de libertad profundos ${ }^{25}$ que aspiran a la resolución de la ruptura actualmente vivida entre la atomización individualista y la dificultad de la empresa colectiva y comunitaria.

En estas circunstancias el propio ejercicio de la libertad ${ }^{26}$ va a ir adquiriendo cada vez más una dimensión nueva de complejidad al insertarse éste como una práctica viable en contextos sociales que disfrutan cada vez de una mayor interdependencia a nivel estructural. Simultáneamente, este ejercicio puede disfrutar hoy también de posibilidades mayores debido a que la confluencia progresiva de las tendencias en apariencia contradictorias de ascetismo y narcisismo, características de nuestra última modernidad, surgen como indicadores paradójicos del potencial moderno de individuación y libertad.

En ese contexto libertad y comunidad no habrian de conjugarse necesariamente como valores ajenos y polarizados, pudiendo mostrarse en ellos la libertad como un indicio de cara a la posibilidad de definir fines comunes y cooperativos amparados en la voluntad de actores que deciden libremente. Posibilidad ésta que nos permitiría avanzar hacia una concepción de la comu-

diversidad interclase y su fuerte dependencia de la variedad de modos de organización social" (Leal y otros, 1988: 70). Una superación ésta que presenta aspectos más genéricos en la dificultad incrínseca del funcionalismo para poder dar cuenta de la complejización progresiva de las sociedades tardomodernas (Rodríguez. Ibáñez, 1989: 167).

24. Inglehart, 1991: 101 y 421: "La liberrad podría definirse como aquella estructura social que fuerza en los hombres una resolución innovadora de los problemas de su vida, sin menoscabar ni sus facultades ni su dignidad humanaw (Giner, 1987: 280).

25. Véase asimismo, Maffesoli, 1988 y Duvignaud, 1990: 44-5.

26. Giner, 1987: 123. 
nidad como aquel espacio en el cual pudiesen ser valoradas, asumidas y respetadas las opciones y exigencias individuales.

Desde ese acto de libertad sería establecible una dinámica diferente capaz de definir necesidades sociales y culturales en ámbitos concretos que tuviesen en cuenta la génesis contingente de los hábitos y las virtualidades de la cultura popular, con engarce en su memoria y que fuese consciente de la vitalidad sociocultural que yace en unos límites y fronteras portadoras de un fuerte potencial de experimentación y creatividad ${ }^{27}$. Esta alternativa es susceptible de ser ensayada en la forma de un proceso dialógico establecido en contextos cooperativos democráticos basados en una proyección asenrada en valores compartidos y con un apoyo en una actitud generalizada y positiva de "egoísmo maduro" ${ }^{28}$. En este sentido, el tema de la construcción social de las necesidades resulta inseparable de la cuestión de los contextos y lógicas que vinculan la realidad sistémica con el mundo de la vida. Asumido el relegamiento de un enfoque de las necesidades sesgado exclusivamente hacia una perspectiva funcional y estrucrural, parece posible empezar a afrontar hoy un modelo abierto que permita la incorporación de comunidades de reflexión y diálogo multipolares y complejas desde las cuales los actores sociales intervengan activamente para definir el carácter y el alcance de las que asuman como sus propias necesidades 29 .

27. Seguimos aquí a Giroux en su afirmación de la cultura — ciudadanía cultutal— acomo un emplazamiento de los límires múltiples y heterogéneos donde las distintas historias, lenguajes, experiencias y voces se entremezclan con distintas relaciones de poder y privilegion (Giroux y otros, 1992: 153).

28. Sobre esto véase (Axelrod, 1986); asimismo Barcellona, 1992: Este ámbito fronterizo, en el caso gallego, remice fundamentalmente a toda la gama de virtualidades lacentes en la resolución posiriva y fecundadora del posible encuentro entre la cultura popular tradicional, los elementos de la cultura moderna y todas las porencialidades inherentes a la cultura ilustrada y a la ciencia. No sólo se trata de aceptar la voz popular, sino de porenciar y experimentar sus virtualidades.

29. En relación con esto resulta pertinente rraer aquí a colación algunas apreciaciones de (Boudon) Boudon (1986: 119, 122, 157); en cuyo trabajo, y a propósito de la hipótesis dialógico-comunitaria de Habermas, se incluyen interesantes aportaciones criticas que a nuestro modo de ver son úriles de cara a la implementación de experiencias prácticas concretas como las que aquí proponemos, ajenas por cierto a todo fin maximalista de comunicación pura y muy apegadas a la arena de las dificultades sobre las que camina toda alternativa de esre tipo. Boudon incluye en su critica aspectos clarificadores relativos a la dificultad concrea de generar espacios de comunicación ideales, aunque nos parece resultar en exceso inflexible cuando centra su atención en la dificultad de extender formulaciones democráticas más abiertas a contextos en los que intervengan cricerios técnicos de autoridad. Su posición parece obviar la capacidad a menudo demostrada de los actores sociales para discernir ante situaciones concreras aquelio que es interpretable y opinable de aquello otro que precisa de ser somerido al peritaje (o peritajes) previo de los técricos. Pertinente, sino necesaria, resulta sin embargo la crítica de Boudon a tenor de un planteamiento como el de Habermas en el cual los aspectos teóricos de carácter filosofico y moral prevalecen de modo claro sobre las problemáticas más concretas que inceresan al sociólogo. Dicho esto, y en relación con lo apuntado más arriba, queremos tambićn dejar claro que nuestro esbozo alternativo, más que a resolver ningún problema, si a algo aspira es precisamente a lo contrario, es decir, a la posibilidad de poner sobre el tapete un problema, el cual, por orra parte, no ciene mucho de nuevo. 
Esta alternativa dialógica y comunitaria, frente a los modos habituales de ser establecidas las necesidades, parece demandar mecanismos generadores específicos, siendo sin duda uno de ellos la producción de espacios de convergencia de lo técnico y lo social que faciliten la incorporación progresiva de instrumentos de investigación participativa y la conversión de los vecinos en ciudadanos capaces de intervenir en la toma de decisiones que les afectan. Para el logro de este objetivo resulta un útil apoyo instrumental la generalización aquilatada y efectiva de fórmulas como el forum comunitario, la contrastación evaluada por parte de miembros de la comunidad de los resultados de otras experiencias equipamentales de referencia al lado de la facilitación de canales de observación, participación y discusión democráticos que promuevan modos originales y rigurosos de decidir las prioridades de necesidad. Estos recursos van a resultar tanto más motivadores cuanto más concretos y locales sean, pudiendo hallar inspiración y apoyo en aquellas líneas de propuesta que con voluntad experimental ensayen intercambios posibles entre comunidad y cultura, o entre memoria, tradición y cultura ilustrada y aún en las potencialidades de mestizaje intercultural susceprible de afiorar en aquellas situaciones caracterizadas por su diversidad étnica y social.

Este itinerario de trabajo sobre los modos de definirse y concretarse las necesidades sociales y culturales camina en paralelo con aquellos planteamientos que se muestran favorables al avance de la democracia, abiertos a la horizontalidad y proclives a que la producción de decisiones no se sustente con exclusividad en validaciones "técnicas" procurando vías originales que puedan ser elaboradas y contrastadas también con el concurso de personas a las cuales no les sean exigidas credenciales excluyentes. Este enfoque supone que las cuestiones de ciudadanía y democracia se abran hacia una perspectiva emancipadora que promueva la responsabilidad social de la base comunitaria frente al predominio habitual de los modelos que optan por primar la capacidad de decisión de las élites tecnopolíticas.

\section{Bibliografia}

ADORno, T. W. y otros (1987). Dialéctica del Iluminismo. Buenos Aires: Sudamericana. ARENOT, H. (1972). La crise de la culture: Huit exercices de pensée politique. París: Gallimard.

Augustin, Jean-Pierre y otros (1987). "Les équipements des jeunes: la fin des illusions". Les cahiers de l'Animation, 61-62, p. I83-200.

AXELROD, R. (1986). La Evolución de La Cooperación. Madrid: Alianza.

BarCellona, P. (1992). Postmodernidad y Comunidad: el regreso de la vinculación social. Madrid: Trotta.

Baret, Yves (1984). La societté du vide. París: Scuil.

BARTHES, R. (1981). Critica y verdad. México: Ed. Siglo XXI.

BATESON, G. y otros (1984). Comunicación la matriz social de la Psiquiatria. Barcelona: Paidos.

BAUDRILLARD, J. (1983). El espejo de la producción. México: Gedisa.

- (1987). América. Barcelona: Anagrama. 
Berger, Peter L. y LUCKMANN, T. (1979). La construcción social de la realidad. Buenos Aires: Amorrortu.

BIOART, C. (1988). "Sociabilités: quelques variables". Revue franfaise de Sociologie, núm. XXIX, p. 621-648.

BOLTANSKI, L. (1982). Les cadres: La formation d'un groupe social. París: Les Éditions de Minuit.

BOUDON, R. (1981). La logica de lo social. Madrid: Rialp.

- (1986). L'idéologie. París: Fayard.

BOURDieu, P. (1979). La distinction. Critique sociale du jugement. París: Les Éditions de Minuit.

- (1985). ¿Qué significa bablar? Economia de los intercambios lingüisticos. Madrid: Akal.

- (1987). Choses dites. París: Les Editions de Minuir.

Chombart de LAUWe, Paul-Henry (1969). Pour une sociologie des aspirations. Paris: Editions Denoël.

- (1988). Culture-action des groupes dominés. Paris: Changements/L'Harmattan.

Clavel, Maité (1986). "Des villes en utopie». En LE GOFF, J. y otros Crise de l'urbain. Futur de la ville. París: Económica, p. 215-218.

COENEN, J. (1970). Loisirs et équipements socio-culturels. Strasbourg; Conseil de L'Europe. Crozier, M. y otros (1977). L'acteur et le système. París: Editions du Seuil.

De BAECQue, A. (1967). Les maisons de la culture. Paris: Seghers.

DeBOrD, Guy (1976). La sociedad del espectáculo. Madrid: Castellote.

DIEM, Jean-Marie (1978), Les équipements sociaux dans l'action sociale. París: Les Editions ESF.

DUMAZEDIER, J. (1988). Révalution culturelle du temps libre 1968-1988. Paris: MéridiensKlincksieck.

DURKHEIM, E. (1976). Educación como socialización. Salamanca: Sigueme.

- (1982a). La división del trabajo social. Madrid: Akal/Universiraria.

- (1982b). El suicidio. Madrid: Akal.

- (1982c). El socialismo. Madrid: Editora Nacional.

- (1982d). Las formas elementales de la vida religiosa. Madrid: Akal.

DUVGNAUD, J. (1990). Herejia y subversión. Ensayos sobre la anomia. Barcelona: Icaria.

ELSTER, J. (1988). «La negación activa y pasiva». En WATZIAWICK y orros, La realidad inventada, Buenos Aires: Gedisa, p. 143-167.

- (1990). El cambio tecnologico. Investigaciones sobre la racionalidad y la transformación social. Barcelona: Gedisa.

FESTINGER, Schachter y otros (1950). Social Pressures in Informal groups. Nueva York: Harper and Bros.

FoucALLT, M. (1983). "Un système fini face à une demande infinie. Entretien avec Michel Foucaultr. En Vv.AA. Sécurité sociale: L'enjeu, Paris: Syros, p. 39-63.

Folrouer, F. y otros (1978). Los equipamientos del poder. Barcelona: Gustavo Gili. GAUDIBERT, P. (1972). Action culturelle: intégration et/ou subversion. París: Casterman. GALLLER, X. (1982). L'avenir à reculons: chômage et retraite. Paris: Les Fditions Ouvriès. GINER, S. (1987). El destino de la libertad. Madrid: Espasa.

GIROUX, H. A. y FLECHA, R. (1992). Igualdad educativa y diferencia cultural. Barcelona: El Roure.

GOMEZ DE LIAÑo, I. (1989). La mentira social. Madrid: Tecnos.

GRIGNON, C. (1982). Sociologie de la culture et sociologie des cultures populaires. ParísNantes: Documents du GiDES-núm. 4. 
GRYSPEERT, A. (1974). Sociologie des interêts culturels. Bruselas: Editions vie Ouvric̀re. HalbWaCHS, M. (1950a). La Mémoire Collective. París: PUF.

- (1950b). Las clases sociales. México: FCE.

Heller, A. (1978). Teoría de las necesidades en Marx. Barcelona: Península.

IBÁNEZ, J. (1986). "Perspectivas de la investigación social». En GARCí FERRANDO, M. y otros, El análisis de la realidad social. Métodos y técnicas de investigación, Madrid: Alianza Universidad Textos, p. 31-65.

INGLEHART, R. (1991). El cambio cultural en las sociedades industriales avanzadas. Madrid: CIS.

KELLER, S. (1975). El vecindario urbano, una perspectiva sociologica. Madrid: Siglo XXI. KUP'ER, L. (1953). Living in Towns. Londres: The Cresset Press.

LABORIT, H. (1973). El hombre y la ciudad. Barcelona: Kairos.

LEAL, J. (1979), "Fundamentos para una análisis de los equipamicntos". En Ciudady Territorio, num, 2, p. 9-14.

LFAL, J. y otros (1988). Los espacios colectivos en la ciudad. Madrid: Ministerio de Obras Públicas y Urbanismo.

LEDRUT, R. (1974). El espacio social de la ciudad. Buenos Aires: Amorrortu.

LLES LAZOO, C. (1980). "Hacia la construcción de stándares para el equipamiento urbano". Revista CEUMT, núm. 28, Batcelona, p. 18-22.

MaCiver, R.M. (1917). Community: A Sociological Study. Londres-Macmillan and Co., Limited.

MAFFESOL, M. (1988). Le temps des tribus. Le déclin de lindividualisme dans les societés de masse. París: Klincksicck.

MALINOWSKI (1970 e. o. 1944). Una teoria cientifica de la cultura. Barcelona: Edhasa.

MARCUSE, H. (1981). El hombre unidimensional. Barcelona: Ariel.

MARTINE\% MARZOA, F. (1983). Filosofia del capital. Madrid:Taurus.

MARTINEZ PARDO, M. (1985). "Reflexiones conceptuales para un marco teótico dc los equipamientos colectivos». CEUMT, octubre, p. 4-8.

MAsLOW, A.H. (1968). Toward a Psychology of being. Nueva York: Van Nostrand Reinhold Co.

MORRIS, R.N. y MOGEY, J. (1965). "The sociology of housing". En Studies at Berinsfield Londres: Routledge \& Kegan Paul.

OCDE (1989). Empleo y Educación a nivel local. Madrid: Minisrerio de Trabajo.

PARETO (1980). Forma y equilibrio sociales. Madrid: Alianza.

Parsons, T. y otros (1951). Toward a General Theory of Action. Cambridge: Harvard University Press.

Passaris, S. y otros (1984). Les associations. París: La Decouverte.

PINÇON, M. (1978). Besoins et habitus. París: Centre de Sociologie Urbaine.

RAPOPORT, A. (1978). Aspectos humanos de la forma urbana. Barcelona: Gustavo Gili.

ROCH, F. (1985). Los equipamientos entre el estándar por casualidad y la imposible necesidad. CEUMT, octubre, p. 23-27.

RODRIGUEZ IBANEZZ, J.E.(1989). La perspectiva sociológica. Madrid: Taurus.

SCHUT2, A. (1974a). El problema de la realidad social. Buenos Aires: Amorrortu.

- (1974b). "Estudios sobre teoría social". Buenos Aires: Amorrortu.

SEgura SANZ, R. y otros (1988). El territorio del consumo colectivo. Problemas y tendencias territoriales en la vivienda y en los equipamientos. Madrid: MOPU.

SIMMEI, G. (1976). Filosofia del dinero. Instituto de Estudios Políticos.

- (1986 e.o. 1908). Sociología, 2. Estudios sobre las formas de socialización. Madrid: Alianza Universidad. 
SOMBART, Werner (1979). Lujo y capitalismo. Madrid: Alianza.

Siriz, Pierre y ocros (1980). Il faut manger pour vivre. Controverses sur les besoins fondamentaux et le développement. París-Genova: PUF-Institut Universitaire d'études du développement.

STACEY, M. (1960). Tradition and change: A Sudy of Banbury. Londres: Oxford Univcrsity Press.

SUMNER, W.G. (1906). Folkways. Boston: Ginn and Co.

VEBLEN, Th. (1971). Teoria de la clase ociosa. México: Fondo de Cultura Económica.

WEBER, M. (1969). Economta y Sociedad. Esbozo de sociologia comprensiva. México: Fondo de Cultura Económica.

- (1984). La acción social. Barcelona: Península.

- (1985). La ética protestante y el espiritu del capitalismo. Barcelona: Orbis.

WEST, J. (1945). Plainville USA. Nueva York: Columbia University Press. 